\title{
Moving towards evidence based emergency medicine: use of a structured critical appraisal journal club
}

\author{
S D Carley, K Mackway-Jones, A Jones, R J Morton, W Dollery, S Maurice, L Niklaus, \\ $S$ Donnan
}

Keeping up to date with new research and clinical developments is one of the major challenges in postgraduate education. ${ }^{1}$ In a broadly based specialty such as emergency medicine this is particularly difficult as relevant articles may be published in a wide spectrum of journals. Estimates of reading times among clinicians have shown that it is impossible for an active clinician to keep up to date by reading journals on an individual basis. $^{2}$

There has been increasing interest about how the principles of evidence based medicine can be introduced into clinical practice and, in common with other specialists, practitioners of emergency medicine are struggling with this problem. Emergency medicine is a relatively new specialty with unique features-in particular single patient episodes, short patient consultations, no ward rounds, a wide scope of practice, a limited research base (especially for more minor complaints), and large numbers of junior doctors led (but rarely directly supervised) by a small number of more senior colleagues. These particular factors mean that many of the established methods for introducing evidence based medicine (which were developed in a different and less pressured context) are unsuitable for use in an emergency department.

In an attempt to overcome some of these problems an evidence based emergency medicine journal club was set up at the Manchester Royal Infirmary in 1997. This had the triple aims shown in box 1 .

R J Morton

W Dollery

$S$ Maurice

L Niklaus

Department of Public

Health and

Epidemiology,

University of

Manchester,

Manchester

$S$ Donnan

Correspondence to: Simon Carley (e-mail: s.carley@btinternet.com).

Accepted for publication 16 April 1998

Box 1

- Teaching critical appraisal techniques

- Keeping abreast of developments

- Introducing the principles of evidence based medicine into practice

This paper outlines the methods by which the aims were achieved and explores how the findings of an evidence based journal club (the evidence for the practice of emergency medicine) can be disseminated into clinical practice.

\section{The journal club}

The journal club meets weekly for approximately one hour. It is held within the emergency department and is open to all medical and nursing staff. The authors represent the initial core members of the club which is now open to clinicians from other departments and hospitals. The aims of the club have been achieved as follows:

\section{TEACHING CRITICAL APPRAISAL OF THE} LITERATURE

A key component to practising evidence based medicine is the ability to interpret the literature. ${ }^{3}$ This ability to critically appraise papers is a key skill for practising emergency physicians and is now a component of the final fellowship in emergency medicine in the UK. ${ }^{4}$ To achieve a basic competence in this skill a series of workshops were constructed based around the critical appraisal text by Crombie. ${ }^{5}$ This was chosen for its brevity and its use of checklists.

The workshop programme is outlined in table 1 . Each session was led by a nominated member of the group with the assistance of one of the senior physicians experienced in critical appraisal.

The series of tutorials were designed to cover the standard types of paper published in journals. ${ }^{6}$ From week 4 to week 9 papers relevant to emergency medicine that utilised the particular methodology under discussion were selected in advance. These papers, which are listed in table 2, were distributed to all group members one week before the workshop so as to allow appraisal before the meeting. In this way the group were able to develop and exercise critical appraisal skills across a range of paper types and standards.

\section{Table 1 Programme of evidence based workshops}

\begin{tabular}{ll}
\hline Week & Topic \\
\hline 1 & Introduction to evidence based medicine \\
& Introduction to critical appraisal \\
2 & Identifying the research method \\
3 & Interpreting the results \\
4 & Introduction to the checklists \\
5 & Standard appraisal questions \\
6 & Appraising surveys \\
7 & Appraising cohort studies \\
8 & Appraising clinical trials \\
9 & Appraising case-control studies \\
\hline
\end{tabular}


Table 2 Papers used in the critical appraisal workshops

Surveys

Are British hospitals ready for the next major incident? Analysis of hospital major incident plans ${ }^{8}$ Skull fractures in children: a population study9

Cohort studies

Does out-of-hospital EMS time affect trauma survival? ${ }^{10}$

Natural evolution of the late whiplash syndrome outside the medicolegal context ${ }^{11}$

Clinical trials

Regional anaesthesia preferrable for Colles' fracture ${ }^{12}$

Randomised trial of intravenous salbutamol in early management of acute severe asthma in children $^{13}$

Case-control studies

Case-control study of stroke and the quality of hypertension in north west England ${ }^{14}$

A population based case-control study of agricultural injuries in children ${ }^{15}$

Review papers

Hypertension soft tissue injuries of the cervical spine-a review ${ }^{16}$

Acute neck sprain: "whiplash" reappraisal ${ }^{17}$

Table 3 Frequency of journal review

\begin{tabular}{ll}
\hline fournal & $\begin{array}{l}\text { Reviews } \\
\text { per year }\end{array}$ \\
\hline Academic Emergency Medicine & 3 \\
Accident and Emergency Nursing & 1 \\
American Journal of Emergency Medicine & 3 \\
Annals of Emergency Medicine & 6 \\
Archives of Disease in Childhood & 2 \\
British Medical Journal & 6 \\
Emergency Nurse & 1 \\
European Journal of Emergency Medicine & 1 \\
Injury & 2 \\
Injury Prevention & 1 \\
Journal of Accident and Emergency Medicine & 3 \\
Journal of Emergency Nursing & 1 \\
Journal of Trauma & 3 \\
Lancet & 6 \\
New England Journal of Medicine & 6 \\
Pre-hospital Immediate Care & 1 \\
Resuscitation & 3 \\
\hline
\end{tabular}

Although the Manchester Royal Infirmary group chose to use the small Crombie book, other books are also available and could be used in a similar way to help develop critical appraisal skills. ${ }^{67}$

\section{KEEPING ABREAST OF CURRENT DEVELOPMENTS} IN EMERGENCY MEDICINE

There are a large number of journals that could contain useful papers for the practising emergency physicians, yet it would be impossible for any one individual to scan, read, and appraise all of them.

Many journal clubs attempt to highlight interesting or relevant papers as a mechanism for changing practice. However, this is often done in an unstructured and haphazard fashion. In order to ensure that important articles were not missed and that time was not wasted on reading irrelevant or poor quality articles a structured approach was taken. A list of 17 peer reviewed journals that were both relevant to the practice of emergency medicine and available for study was formulated. Each journal was assigned a number of times to be reviewed per year (the review rate reflecting both the number of issues in a year and the estimated chances of quality emergency medicine papers appearing). The list of journals and their review rates are shown in table 3.

Table 4 Strength of evidence

\begin{tabular}{ll}
\hline A & There is good evidence to support the use of the procedure \\
B & There is fair evidence to support the use of the procedure \\
C & There is poor evidence to support the use of the procedure \\
D & There is fair evidence to support the rejection of the procedure \\
E & There is good evidence to support the rejection of the procedure \\
\hline
\end{tabular}

Only the best, most relevant, or interesting articles from the journal of the week are presented to the other members of the journal club. As was the case during the initial workshops papers are made available one week in advance and are appraised using the checklists from the critical appraisal guide..$^{5-7}$ Papers are rated using the categorisation of evidence shown in table $4 .{ }^{18}$ Compelling evidence from high quality papers is integrated into departmental policy.

This structured approach ensures that important papers are not overlooked by individual members of the journal club. In total 49 sessions per year are allocated to particular journals. Since two papers are reviewed each week at least 98 papers are critically appraised by the group per year.

On several occasions no high quality papers have been found after the review of the journal. In this case lower quality papers are reviewed and study design improvements are discussed. This process educates the group in research design as well as in critical appraisal. Furthermore potential research topics have been highlighted in this way.

INTRODUCING EVIDENCE BASED MEDICINE INTO PRACTICE "MAKING BETS"

It could be argued that evidence based practice can be introduced into emergency medicine merely by scanning and appraising journals as outlined above; it is certainly the case that some changes in practice have come about in this way. However this process of learning is not an accurate reflection of clinical practice since it is patients not journal articles that present to the emergency department. Clinical practice is based around making decisions on real patients, and it is essential that evidence based medicine reflects this. Thus evidence that pertains to questions that arise during clinical encounters should also be addressed. As described elsewhere in this journal ${ }^{19}$ we have modified the critically appraised topic technique for use in emergency medicine. The reports generated, called best evidence topic reports (BETs), are used to introduce and change clinical practice within the emergency department.

Topics for BETs are selected by the group and each week one member of the group presents a report.

\section{Discussion}

Structured journal clubs are not new to emergency medicine ${ }^{20-22}$ but we believe that this is the first report of a journal club being used to implement evidence based practice in an emergency department. Many emergency departments and training rotations in the UK participate in journals clubs of some kind. Experience has shown these to be unstructured and rather haphazard affairs that do little to establish the practice of evidence based medicine. With evidence based medicine becoming an ever more important aspect of training and clinical practice we advocate the structure described here to other emergency medicine journal clubs.

No formal assessment of group satisfaction was undertaken before and after the 
development of the journal club. Anecdotally we found that participants did not feel that their reading time had significantly increased. However, their reading time was more focused, critical, and across a much wider range of journals. Overall the members of the group consider the journal club to be a success, and an effective use of the limited amount of time available for private study in a busy emergency department.

We have not assessed the impact of the journal club on clinical practice and patient care within the department as no data was collected prior to the development of the journal club system. Anecdotally lessons learned from BETs and structured journal scans have been implemented within the department.

Emergency medicine has close links with a large number of other specialties. It is important that evidence used in the emergency department is shared with in hospital specialties and on call teams. We believe that the construction and dissemination of the BETs can aid this interspecialty liaison and improve clinical practice.

\section{Conclusion}

Traditional methods of instituting evidence based medicine are not applicable to the emergency department setting. A structured journal club was designed to teach critical appraisal, keep abreast of developments in the field of emergency medicine, and institute evidence based medicine in this setting.

A proactive approach to evidence based medicine is necessary in emergency medicine. The use of a journal club to critically appraise journals relevant to emergency medicine and to construct and disseminate BETs, is one mechanism by which this can be achieved.

1 Sackett DL, Haynes RB, Guyatt GH, et al. Clinical epidemiology - a basic science for clinical medicine. London: Little Brown, 1991: 187.
2 Davidoff F, Haynes B, Sackett D, et al. Evidence-based medicine. A new journal to help doctors identify the information they need. BMJ 1995;310:1085-6.

3 Greenhalgh T. "Is my practice evidence based?" BMJ 1996; 313:957-8.

4 Board of the Faculty of Accident and Emergency Medicine. Guidelines for specialist training in accident and emergency medicine. London: Faculty of Accident and Emergency Medicine, 1996.

5 Crombie IK. The pocket guide to critical appraisal. London BMJ Publishing Group, 1996.

6 Greenhalgh T. How to read a paper: the basics of evidence based medicine. London: BMJ Publishing Group, 1997.

7 Sackett DL, Richardson WS, Rosenberg W, et al. Evidence based medicine-how to practice and teach EMB. London: Churchill-Livingstone, 1996.

8 Carley S, Mackway-Jones K. Are British hospitals ready for the next major incident? Analysis of hospital major inciden plans. BMJ 1996;313:1242-3.

9 Johnstone AJ, Zuberi SH, Scobie WG. Skull fractures in children: a population study. J Accid Emerg Med 1996;13: 386-9.

10 Feero S, Hedges JR, Simmons E. Does out-of-hospital EMS time affect trauma survival? Am J Emerg Med 1995;13. 133-5.

11 Schrader $\mathrm{H}$, Obelieniene D, Bovim G, et al. Natura evolution of the late whiplash syndrome outside the medicolegal context. Lancet 1996;347:1207-11.

12 Abbaszadegan $\mathrm{H}$, Jonsson U. Regional anaesthesia preferable for Colles' fracture. Controlled comparison with local anethesia. Acta Orthop Scand 1990;61:348-9.

13 Browne GJ, Penna AS, Phung X, et al. Randomised trual of intravenous salbutamol in early management of acute servere asthma in children. Lancet 1997;349:301-5.

$14 \mathrm{Du}$ X, Cruikshank K, McNamee R, et al. Case-control study of stroke and the quality of hypertension control in north west England. BMJ 1997;314:272-6.

15 Stueland DT, Lee BC, Nordstrom DL, et al. A population based case-control study of agricultural injuries in children. Inj Prev 1996;2:192-6.

16 Johnson G. Hyperextension soft tissue injuries of the cervical spine-a review. J Accid Emerg Med 1996;13:3-8.

17 Hammacher ER, van der Werken Chr. Acute neck sprain: "whiplash" reappraised. Injury 1996;27:463-6.

18 Stevens A, Raftery J, eds. US task force on preventative health care. Health care needs assessment: the epidemiologically based needs assessment reviews. Second series. Oxford: Radcliffe Medical Press, 1997.

19 Mackway-Jones K, Carley SD, Morton RJ, et al. The best evidence topic report: a modified CAT for summarising the evidence topic report: a modified CAT for summarising the available evidence in

20 Burstein JL, Hollander JE, Barlas D. Enhancing the value of journal club: use of a structured review instrument. Am Emerg Med 1996;14:561-3.

21 Krough CL. A checklist system for critical review of medical literature. Med Educ 1985;19:392-5.

22 Markett RJ. A research methods and statistics journal club for residents. Acad Med 1989;April:223-4.

\section{Department of}

Emergency Medicine,

Manchester Royal

Infirmary, Oxford

Road, Manchester

M13 9WL

K Mackway-Jones

S D Carley

R J Morton

Department of Public

Health and

Epidemiology,

University of

Manchester,

Manchester

$S$ Donnan

Correspondence to: Kevin Mackway-Jones

(e-mail:kmackway@

fs1.mci.man.ac.uk).

Accepted for publication 16 April 1998

\title{
The best evidence topic report: a modified CAT for summarising the available evidence in emergency medicine
}

\author{
K Mackway-Jones, S D Carley, R J Morton, S Donnan
}

In order to achieve the optimal care for patients in the emergency department it is essential that their management is based upon the best available evidence. While the concept of evidence based medicine is widely accepted across many hospital and community specialties, emergency medicine has lagged behind in formalising the approach to evidence based practice.

One commonly used approach is that of the critically appraised topic (CAT). ${ }^{12}$ This was designed to be a one page summary of the evidence related to a particular clinical question. This established method would appear to be a reasonable starting point for developing a clinically based approach to examining the evidence in emergency medicine. Unfortunately problems have been identified. CATs work best when based on papers that stand up to rigorous critical appraisal. In emergency medicine the evidence that does exist is frequently not of high quality, and consequently the critical appraisal process would tend to discard many papers because of either methodological flaws or poor design. The experience of the critical appraisal journal club $^{3}$ was that an absolute requirement for high quality evidence meant 